\title{
Volcanic deformation of Atosanupuri
} volcanic complex in the Kussharo caldera, Japan, from 1993 to 2016 revealed by JERS-1, ALOS, and ALOS-2 radar interferometry

\author{
Satoshi Fujiwara ${ }^{1 *} \mathbb{D}$, Makoto Murakami ${ }^{2}$, Takuya Nishimura ${ }^{3}$, Mikio Tobita ${ }^{1}$, Hiroshi Yarai $^{1}$ \\ and Tomokazu Kobayashi ${ }^{1}$
}

\begin{abstract}
A series of uplifts and subsidences of a volcanic complex in the Kussharo caldera in eastern Hokkaido (Japan) has been revealed by interferometric analysis using archived satellite synthetic aperture radar data. A time series of interferograms from 1993 to 1998 showed the temporal evolution of a ground deformation process. The horizontal dimension of the deformation field was about $10 \mathrm{~km}$ in diameter, and the maximum amplitude of the deformation was $>20 \mathrm{~cm}$. Uplift started in 1994, and concurrent earthquake swarm activity was observed around the uplift area; however, no other phenomena were observed during this period. A subsidence process then followed, with the shape of the deformation forming a mirror image of the uplift. Model simulations suggest deformation was caused by a source at the depth of about $6 \mathrm{~km}$ and that the position of the source remained static throughout the episode. Subsidence of the volcanic complex was also observed by another satellite from 2007 to 2010, and likely continued for more than 10 years. In addition to the main uplift-subsidence sequence, small deformation patterns with short spatial wavelengths were observed at the center of the deforming area. Data from three satellites recorded small-scale subsidence of the Atosanupuri and Rishiri lava domes at a constant rate of approx. $1 \mathrm{~cm} /$ year from 1993 to 2016.
\end{abstract}

Keywords: Kussharo caldera, Atosanupuri volcanic complex, Volcanic uplift and subsidence, SAR interferometry

\section{Introduction}

Observation of crustal deformation around a volcano provides important information about the dynamic processes of the transfer of volcanic fluids that could lead to an eruption. Continuous GNSS (Global Navigation Satellite System) measurements at permanent sites are now used commonly for monitoring the crustal deformation of volcanoes. However, volcanic deformation is frequently localized within a small area and thus, a very dense network of GNSS receivers would be necessary to capture all the deformation features. It is often difficult to achieve a GNSS network with such density because of

\footnotetext{
*Correspondence: fujiwara-s2vq@mlit.go.jp

1 Geospatial Information Authority of Japan, 1 Kitasato, Tsukuba, Ibaraki 305-0811, Japan

Full list of author information is available at the end of the article
}

the ruggedness of terrain, lack of prerequisite infrastructure such as electricity and cabling for signal transmission, and harsh conditions caused by volcanic activity. L-band synthetic aperture radar (SAR) interferometry (InSAR) has many advantages in relation to volcanic monitoring, and it has become a standard tool for monitoring deformation of the Earth's surface (e.g., Chaussard et al. 2013; Fournier et al. 2010; Fujiwara et al. 1998). This remote sensing technique is capable of mapping deformation fields over large areas to a high degree of accuracy (i.e., a few centimeters) without need for ground-based measurement facilities. The Japanese Earth Resources Satellite (JERS-1) launched by NASDA [now the Japan Aerospace Exploration Agency (JAXA)] is one such satellite equipped with L-band sensors, and it acquired a large volume of data globally during 1992-1998. To verify the capability of L-band InSAR when applied to 
volcano monitoring, we performed InSAR analyses using improved processing algorithms (Fujiwara et al. 1998; Tobita et al. 1998) to discover magmatic crustal deformation that could not be detected using other geodetic techniques.

The Kussharo (also called Kutcharo) caldera in eastern Hokkaido (Fig. 1), which formed about 30,000 years ago (Katsui 1962), is the largest caldera in Japan. It is $26 \mathrm{~km}$ wide $(\mathrm{E}-\mathrm{W})$ and $20 \mathrm{~km}$ long $(\mathrm{N}-\mathrm{S})$, and it encompasses Lake Kussharo. The Atosanupuri caldera (approx. $4 \mathrm{~km}$ in diameter, see Fig. 1) is a younger volcanic complex that fills the eastern half of the Kussharo caldera. Within the volcanic complex, 10 lava domes formed in this $15 \mathrm{ka}$ after the Atosanupuri caldera forming eruption of 20 ka (Hasegawa et al. 2009, 2013; Japan Meteorological Agency 2013), which is associated with pyroclastic deposits. The Atosanupuri lava dome (also called Mount Iou), located in the northeastern part of the complex (Fig. 1), is the youngest of these domes and has ongoing fumarolic activity on its surface (e.g., Japan Meteorological Agency 2013; Katsui et al. 1986). Although geological data suggest that the latest phreatic eruption occurred at the Atosanupuri lava dome several hundred years ago, there is no historical record of the eruption because of the remoteness of the site from cultural centers of the time (e.g., Japan Meteorological Agency 2013; Katsui et al. 1986). This suggests the possibility of a future eruption and the need for further studies to understand the underlying magmatic system.

\section{Data and methods}

In this study, we used the L-band SAR data of JERS1, Advanced Land Observing Satellite (ALOS), and Advanced Land Observing Satellite 2 (ALOS-2). The use of L-band (longer wavelength than C-band) SAR is essential in the application of this technology for areas covered by thick vegetation, as is the case in Japan (e.g., Fournier et al. 2010; Rosen et al. 1996). The SAR data were

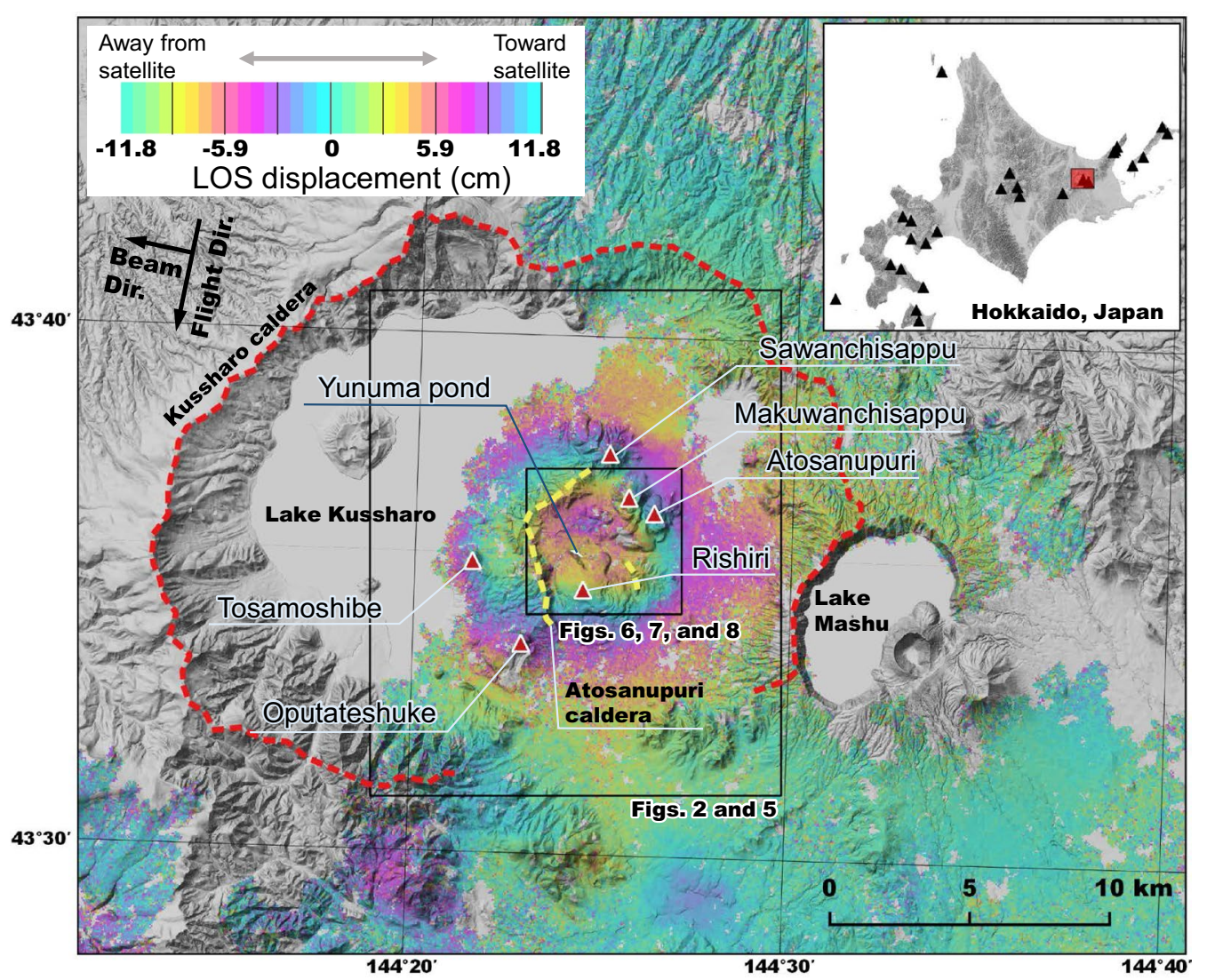

Fig. 1 A SAR interferogram showing range change between JERS-1 and the ground surface during the period from August 13, 1993 to April 21, 1995, overlaid on topographic relief of the study target area. Area of the color change at the center is the signature of the deformation detected by JERS-1 InSAR. Color scale indicates radar range change (positive values show upward and/or east-southeastward displacement). Red dashed line shows the approximate boundary of the Kussharo caldera, and the yellow dashed line shows the Atosanupuri caldera (Katsui 1962). Red triangles indicate major lava domes belonging to the Atosanupuri volcanic complex. Rectangles with figure numbers show the area of each figure. Location of this figure is shown in the inset. Black triangles in the inset indicate active volcanoes 
processed using the GSISAR software package (Fujiwara and Tobita 1999; Fujiwara et al. 1999; Tobita 2003; Tobita et al. 1999). In GSISAR, an adaptive filter (Goldstein and Werner 1998) was used to remove noise on interferograms and phase unwrapping (Goldstein et al. 1998) was also applied. A 50-m-mesh DEM (Murakami 1995) was used to remove the effect of topography for JERS-1, and a 10-m-mesh DEM (Geospatial Information Authority of Japan 2016) was used for ALOS and ALOS-2. First, we calculated InSAR deformation maps (interferograms) spanning the period from May 1993 to July 1998 using JERS-1 data. We used radar data acquired from descending orbits, in which the satellite looks down on the Earth's surface from the east-southeast direction. The measured crustal deformation reflects the change in range distance between the ground target and the satellite along the radar line-of-sight (LOS) direction, and the off-nadir angle was $35^{\circ}$. For JERS-1, we selected as many InSAR pairs as possible with small baselines (Table 1), which mitigated the poor radar coherence of the interferograms. For ALOS and ALOS-2, long durations were selected to account for the small time changes. Time series analyses (e.g., SBAS, Berardino et al. 2002; PSInSAR, Hooper et al. 2004) were not used in this study because the number of
InSAR pairs was limited and deformation did not change linearly with time.

For geodetic inversion, we used the formulas reported by Okada (1985) to calculate surface deformations by a source buried in a homogeneous elastic half-space. We followed the nonlinear inversion method of Matsu'ura and Hasegawa (1987) to estimate the parameters of a pressure source. We tested two different pressure sources: (1) a point source (Mogi 1958) and (2) a horizontal planar source (sill). In some cases, results may depend on the input initial value of the model simulation. For the Mogi source, results of depth depend on the initial volume; therefore, we selected the initial volume value to minimize the Akaike information criterion (AIC).

\section{Results}

Figure 1 shows a typical deformation field mapped by InSAR from August 1993 to April 1995 along with the topography of the study area. The area of changing colors at the center of the figure depicts the deformation of the ground surface. The horizontal dimension of the deforming area is about $10 \mathrm{~km}$ in diameter, and it covers almost the entire area of the Atosanupuri volcanic complex. The maximum range change due to surface deformation was observed near the center of the deforming area,

Table 1 List of interferograms analyzed

\begin{tabular}{|c|c|c|c|c|c|c|c|}
\hline $\begin{array}{l}\text { InSAR } \\
\text { pair }\end{array}$ & $\begin{array}{l}\text { Acquisition date } \\
\text { master image }\end{array}$ & $\begin{array}{l}\text { Acquisition date } \\
\text { slave image }\end{array}$ & $\begin{array}{l}\text { Time span } \\
\text { (day) }\end{array}$ & $\mathrm{Bp}(\mathrm{m})$ & $\begin{array}{l}\text { Time } \\
\text { series }\end{array}$ & $\begin{array}{l}\text { Maximum } \\
\text { displacement }(\mathrm{cm})\end{array}$ & $\begin{array}{l}\text { Corrected maximum } \\
\text { displacement }(\mathrm{cm})\end{array}$ \\
\hline 1 & May 18, 1993 & May 9, 1997 & 1452 & 159 & $C$ & 13 & 13 \\
\hline 2 & August 13, 1993 & April 21, 1995 & 616 & -663 & $A$ & 19 & 20 \\
\hline 3 & August 13, 1993 & July 22, 1998 & 1804 & 45 & A & $10^{*}$ & $8^{*}$ \\
\hline 4 & September 13, 1994 & August 31, 1995 & 352 & -527 & B & 6 & 6 \\
\hline 5 & September 13, 1994 & April 25, 1998 & 1320 & -193 & B & -2 & -2 \\
\hline 6 & April 21, 1995 & April 7, 1996 & 352 & 736 & A & -3 & -3 \\
\hline 7 & April 21, 1995 & July 22, 1998 & 1188 & 712 & A & -9 & -9 \\
\hline 8 & July 19, 1995 & June 9, 1998 & 1056 & 478 & $\mathrm{D}$ & -11 & -11 \\
\hline 9 & July 19, 1995 & July 23, 1998 & 1100 & -186 & $\mathrm{D}$ & -7 & -7 \\
\hline 10 & August 31, 1995 & October 31, 1997 & 792 & -556 & B & -4 & -4 \\
\hline 11 & August 31, 1995 & April 25, 1998 & 968 & 333 & B & -7 & -7 \\
\hline 12 & April 7, 1996 & March 25, 1997 & 352 & 985 & A & -6 & -5 \\
\hline 13 & March 25, 1997 & June 8, 1998 & 440 & 227 & A & -3 & -3 \\
\hline 14 & June 9, 1998 & July 23, 1998 & 44 & -659 & $D$ & 3 & 3 \\
\hline A1 & September 22, 2007 & August 15, 2010 & 1058 & 819 & $E$ & -6 & -5 \\
\hline A2 & May 9, 2008 & November 15, 2010 & 920 & 310 & $\mathrm{~F}$ & -4 & -4 \\
\hline A3 & August 9, 2014 & August 6, 2016 & 728 & -47 & G & -1 & 0 \\
\hline A4 & August 25, 2014 & June 13, 2016 & 658 & 22 & $\mathrm{H}$ & -2 & -1 \\
\hline A5 & September 29, 2014 & July 4, 2016 & 644 & 8 & I & -1 & 0 \\
\hline
\end{tabular}

JERS-1 data are used in InSAR pairs 1-14, ALOS data are used in A1 and A2, and ALOS-2 data are used in A3, A4, and A5. InSAR data were acquired from descending orbit except for InSAR pair A4. The off-nadir angle of JERS- 1 is $35^{\circ}$, and that of $A 1, A 2, A 3, A 4$, and $A 5$ is $34.3^{\circ}, 34.3^{\circ}, 29.1^{\circ}, 32.4^{\circ}$, and $38.2^{\circ}$, respectively. Bp means a perpendicular baseline. There are nine time series; A-I. Temporal evolution of displacement can be obtained only from InSAR pairs belonging to the same time series. Maximum displacement shows the maximum displacement in LOS direction in each SAR interferogram. Corrected maximum displacement is obtained by subtracting constant small-scale displacement from the maximum displacement. *Because InSAR pair 3 was highly decorrelated and noisy, the maximum displacement value was not reliable 
and it reached approximately $20 \mathrm{~cm}$ displacement in the direction toward the satellite (upward and/or east-southeastward displacement). In this study, we interpreted that observed radar LOS displacements indicate crustal uplift/subsidence of the Atosanupuri volcanic complex (e.g., Fialko and Simons 2001). As a matter of course, we paid attention to the fact that LOS displacement includes horizontal components (e.g., Segall 2010).

Figure 2 shows all the unwrapped interferograms of JERS-1 used in this study, and the parameters of each interferogram are presented in Table 1. Figure 3 shows the relative temporal variation of the LOS displacement of the maximum deformation of each interferogram of Fig. 2. These figures indicate that large uplift of the volcanic complex occurred between 1993 and 1995, which subsequently turned to subsidence. The rate of uplift in the LOS direction was approx. $10 \mathrm{~cm} /$ year, and that of subsidence was approx. $4 \mathrm{~cm} /$ year.

Net deformation in mid-1998 was about half the peak in 1995. It is interesting to note that an earthquake swarm was observed in 1994 (Earthquake Research Institute 2002). Earthquake depths were less than $10 \mathrm{~km}$, and the largest magnitude of this swarm event was 3.2. Since 1950, several earthquakes > M5.0, including an M6.5 event in 1967, have been recorded near the volcano (Katsui et al. 1986). However, the epicenters of these large earthquakes were distributed within an area about $10 \mathrm{~km}$ southwest of the volcano. The earthquake swarm in 1994 was unique because the epicenters were just beneath the Atosanupuri volcanic complex (Motoya and Ichiyanagi 1996). Another small earthquake swarm was recorded in 1998 (Fig. 3), and it is interesting that the only uplift observed after 1995 occurred from June to July 1998.

We inverted the observed deformation during 19931995 trying both spherical pressure and planar tensile sources (Fig. 4). Figure 4e shows a cross section of the observed and best-fit model simulations, and Table 2 lists the model parameters. The point source model cannot express well the shape of the deformation along some profiles; for example, as shown in Fig. 4e, the model of a bell-shaped deformation dome is steeper than the observations and the center of the model is shifted to the west side in this cross section. In comparison with the point source model ( $\mathrm{rms}$ of the residuals is $2.2 \mathrm{~cm}$ ), the sill model ( $\mathrm{rms}$ of the residuals is $2.0 \mathrm{~cm}$ ) matched the observations better.

We also inverted the subsiding deformation from July 1995 to June 1996 to estimate all the parameters. We found the horizontal position and the shape of the sill during subsidence to be almost identical to those during uplift. Although a difference $(\sim 700 \mathrm{~m})$ in the depths of the sills between subsidence and uplift was found, it was probably attributable to interferogram errors of several centimeters. This finding indicates the position of the source remained static throughout the entire uplift-subsidence episode during 1993-1998.

Unfortunately, the JERS-1 satellite ceased operation in October 1998; therefore, it was not possible to trace directly the further evolution of this event. Although a GNSS station was installed to the northeast of the Atosanupuri lava dome in 2006, no particular deformation has been found (see Additional file 1: Fig. S1). Furthermore, we analyzed data obtained by two newer SAR satellites: ALOS (2006-2011) and ALOS-2 (2014-) operated by JAXA (Fig. 5). It is interesting that the subsidence of the Atosanupuri volcanic complex was also observed by ALOS (A1 and A2 in Fig. 5). As the subsidence rate in the LOS direction was approx. $2 \mathrm{~cm} /$ year and the shape of the deformation was similar to those observed by JERS1 , the subsidence rate became smaller but continued for more than 10 years.

\section{Discussion}

\section{Small-scale deformation}

It is interesting to note that the shape of deformation in Figs. 2 and 5 is described by a composite of a larger bell-shaped dome and other small patterns. Small-scale deformation signals are commonly observed in the model's residuals; however, we had difficulties in calculating the best-fit model for all interferograms. There are several reasons for the difficulties: (1) the interferograms of JERS-1 suffer from decorrelation noise; (2) the atmospheric noise is particularly larger in longer wavelengths (Fujiwara et al. 1998); and (3) the small deformation patterns exist close to the center of the bell-shaped deformation dome, where they interfere with each other. As the bell-shaped deformation dome has a wavelength of about $10 \mathrm{~km}$ (Figs. 2, 4), we constructed high-pass-filtered (7 km cutoff) close-up images of the center of the deformation dome (Figs. 6, 7) to investigate the small and short spatial wavelength (hereafter, "small-scale") features. In other words, the high-pass filter was applied to remove the larger bell-shaped deformation and the longer wavelength noise. We found two features of the small-scale deformations: (1) a small-scale deformation valley sitting on top of the larger bell-shaped deformation dome and (2) subsidence of the northwest of the Rishiri dome. The magnitude of the small-scale pattern was at most $2-3 \mathrm{~cm}$ and was close to the noise level of JERS-1 InSAR observations (Fujiwara et al. 1998). Some of the most significant noise in an interferogram is atmospheric (Fujiwara et al. 1998; Hanssen 2001); however, since atmospheric noise has a longer wavelength (Fujiwara et al. 1998), the short wavelength deformations in the interferograms were probably not associated with atmospheric noise. Moreover, similar deformations were found in several 


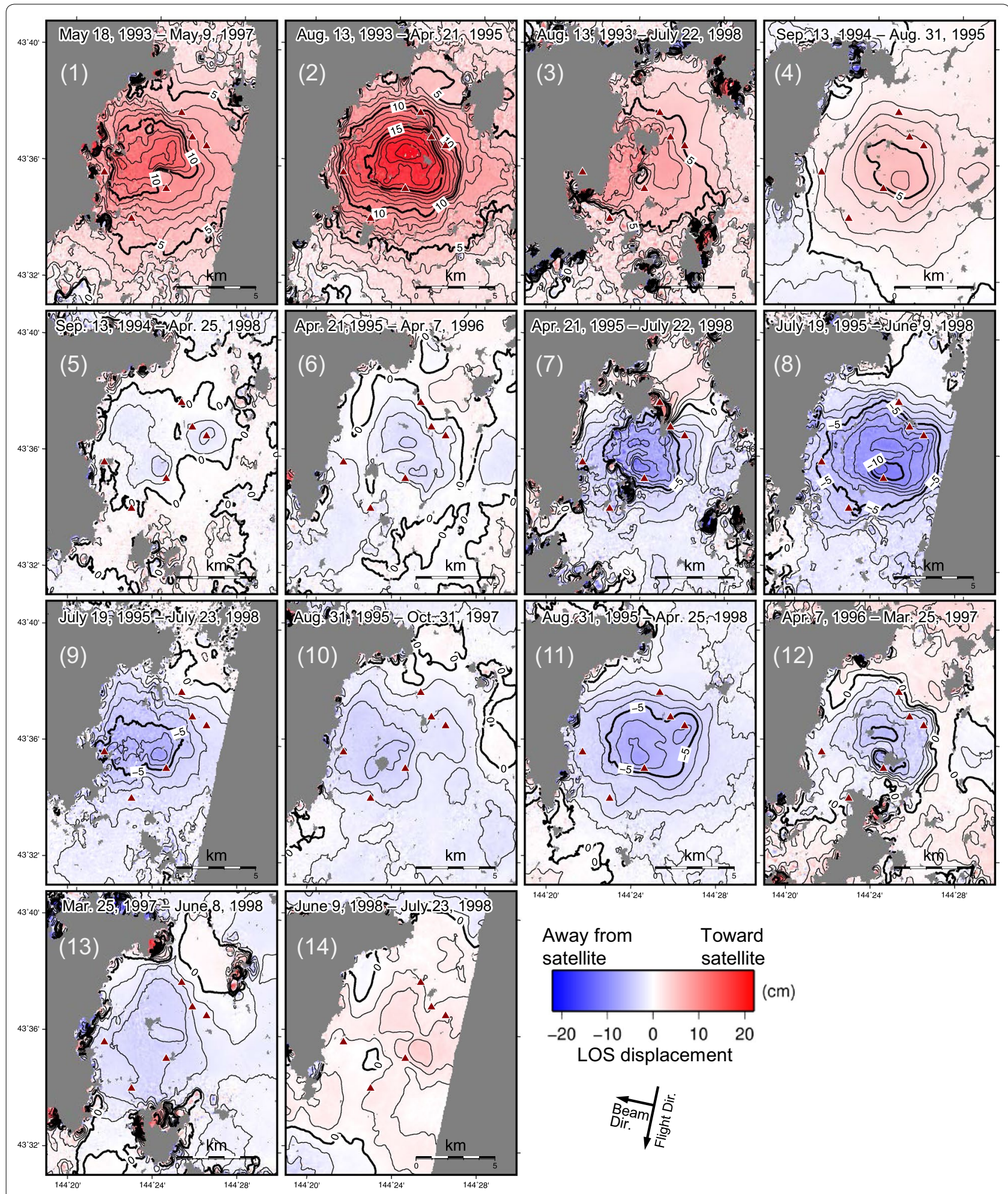

Fig. 2 Unwrapped SAR interferograms of JERS-1 used in this study. Each number indicates the InSAR pair in Table 1. Red triangles indicate major lava domes belonging to the Atosanupuri volcanic complex. Contour interval is $1 \mathrm{~cm}$. The target area is shown in Fig. 1 


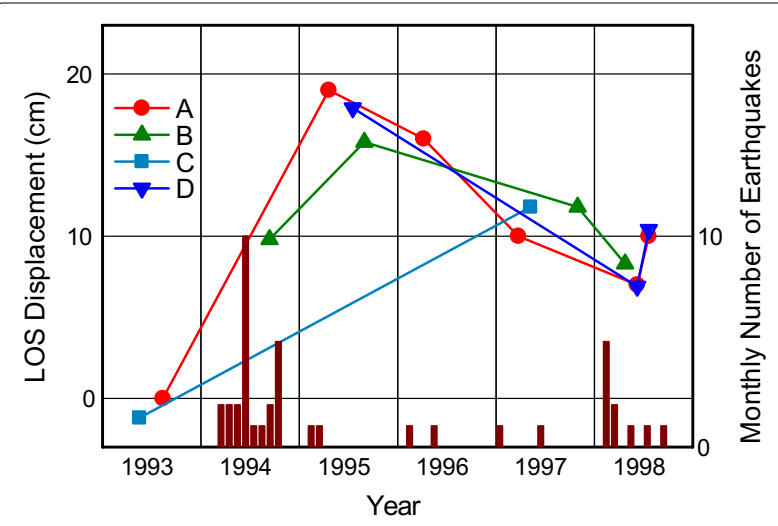

Fig. 3 Temporal evolution of the maximum LOS displacement in each interferogram near the center of the deformation field. Positive values show upward and/or east-southeastward displacement. Each time series $A-D$ shows independent time change defined in Table 1. In this figure, each time series is shifted vertically to show the smallest variation between the time series. The monthly number of earthquakes within the region (Fig. 2) is also plotted (Earthquake Research Institute 2002), including earthquakes with magnitudes of larger than 0.3 and depths of shallower than $20 \mathrm{~km}$

interferograms taken on different dates and it is unlikely that the same atmospheric effects would have occurred on different data acquisition dates (Fujiwara et al. 1998). A 50-m-mesh DEM was used to remove the effects of topography for JERS-1; therefore, errors in the DEM would propagate into the deformation results depending on the baseline (Bp in Table 1) characteristics (Hanssen 2001). The accuracy of the DEM was $7 \mathrm{~m}$ (Murakami 1995). If there were a $7 \mathrm{~m}$ error in the DEM, the LOS displacement error would have been approximately $1.4 \mathrm{~cm}$ for the largest Bp $(985 \mathrm{~m})$ of InSAR pair 12 in Table 1. Figure 6 also shows the topography of the same area. It is interesting to note that the valley of the deformation coincides with a small valley (or basin) between volcanic lava domes in the topography. However, because the sense of LOS displacements of each small valley deformation is correlated with their baseline in Table 1, the DEM error might have affected the small deformations. However, InSAR pairs A3, A4, and A5 have very small baselines because of the good control of the satellite orbit of ALOS-2; therefore, the interferograms of A3, A4, and A5 have little DEM error and they show similar deformation in the small valley. Therefore, we are satisfied there was real surface deformation in the small valley despite the DEM error.

As for the deformation signal of the northwest of the Rishiri dome, the displacements of each deformation are not related to their baseline, and the deformations are clearly recognized in InSAR pairs such as $1,3,5,7$, 8,9 , and 11, which have longer time spans (>900 days).
Therefore, the signals in the interferograms on the Rishiri dome most probably reflect real surface deformation. Figure 7 shows the same deformation of the Rishiri dome continued during 2007-2010 and 2014-2016. Although InSAR pairs A3, A4, and A5 have different off-nadir angles and look directions, the shapes of the small-scale deformation of the Rishiri dome resemble each other; therefore, horizontal displacements are likely small and the small-scale deformations consist mainly of vertical displacement. We calculated vertical displacement from LOS displacement using the incident angle of each observation assuming that the horizontal displacement was small enough. To reduce noise in Figs. 6, 7, we constructed Fig. 8 that shows the average yearly rate of height change (vertical displacement calculated from LOS change), assuming the rate of the small-scale deformation was almost constant in each period (1993-1998, 2007-2010, and 2014-2016). In contrast, the rate of the larger bell-shaped deformation was not constant. Several observations can be made based on Fig. 8: (1) the Rishiri dome subsided at a constant rate (at most, approximately $0.8 \mathrm{~cm}$ per year at the surface) in the different time periods; (2) other subsidence existed around the Atosanupuri dome, although the subsidence area was not the same in the different time periods; and (3) the small valley was inflated in all time periods. Since the horizontal dimension of the deformation field of the Rishiri dome is $<2 \mathrm{~km}$, the source of the deformation likely existed within a shallow area (depth: $\sim 1 \mathrm{~km}$ ) in the lava dome. As it is perhaps unreasonable to assume the same subsidence occurred in the three periods independently, it is natural to consider that subsidence continued in all the periods and that the time constant (timescale of exponential decay) of the subsidence was likely $>20$ years. The Rishiri dome was formed about 5500 years ago with pyroclastic ejecta; however, no volcanic activity such as an eruption has been recorded since (Japan Meteorological Agency 2013). Separately from the larger bell-shaped deformation in the Atosanupuri caldera, a complex source geometry could exist and the Rishiri lava dome could have been cooling and subsiding.

\section{Uplift and subsidence series}

We now discuss possible scenarios for the ground deformation of the larger bell-shaped dome related to magmatic processes. Based on the above results and calculations, the deformations in Figs. 2 and 5 contain not only the larger bell-shaped dome but also the small-scale deformations. We assumed the small-scale deformations were constant in each period and subtracted them from the original deformation shown in Figs. 2 and 5, according to the duration of each period. The corrected SAR interferograms are shown in Additional file 1: Fig. S2, and 


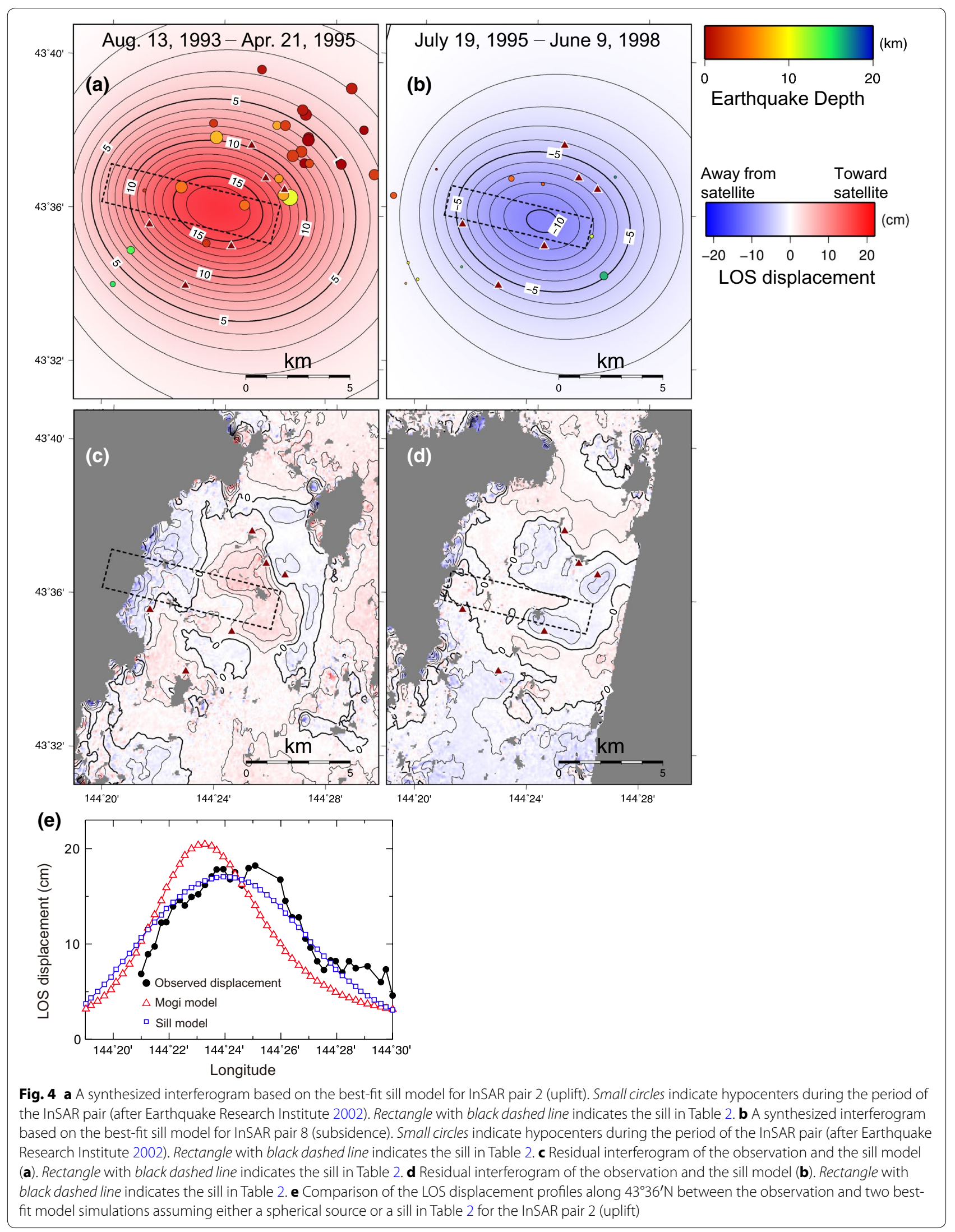


Table 2 Calculated volcanic source parameters

\begin{tabular}{lllllcrcr}
\hline InSAR pair & Source type & Depth $(\mathbf{k m})$ & Width $(\mathbf{k m})$ & Length $(\mathbf{k m})$ & Strike $\left({ }^{\circ}\right)$ & Open $(\mathbf{m})$ & Volume $\left(\mathbf{m}^{\mathbf{3}}\right)$ & rms of residuals $(\mathbf{c m})$ \\
\hline 2 & Mogi & $5.5 \pm 0.1$ & - & - & - & - & $2.8 \times 10^{7}$ & 2.2 \\
2 & Sill & $6.0 \pm 0.2$ & $8.4 \pm 0.4$ & $1.9 \pm 0.7$ & $12.2 \pm 2.9$ & $1.4 \pm 0.6$ & $2.2 \times 10^{7}$ & 2.0 \\
8 & Sill & $5.3 \pm 0.2$ & $7.1 \pm 0.4$ & $1.4 \pm 0.7$ & $5.0 \pm 2.9$ & $-1.0 \pm 0.5$ & $-1.0 \times 10^{7}$ & 1.3 \\
\hline
\end{tabular}
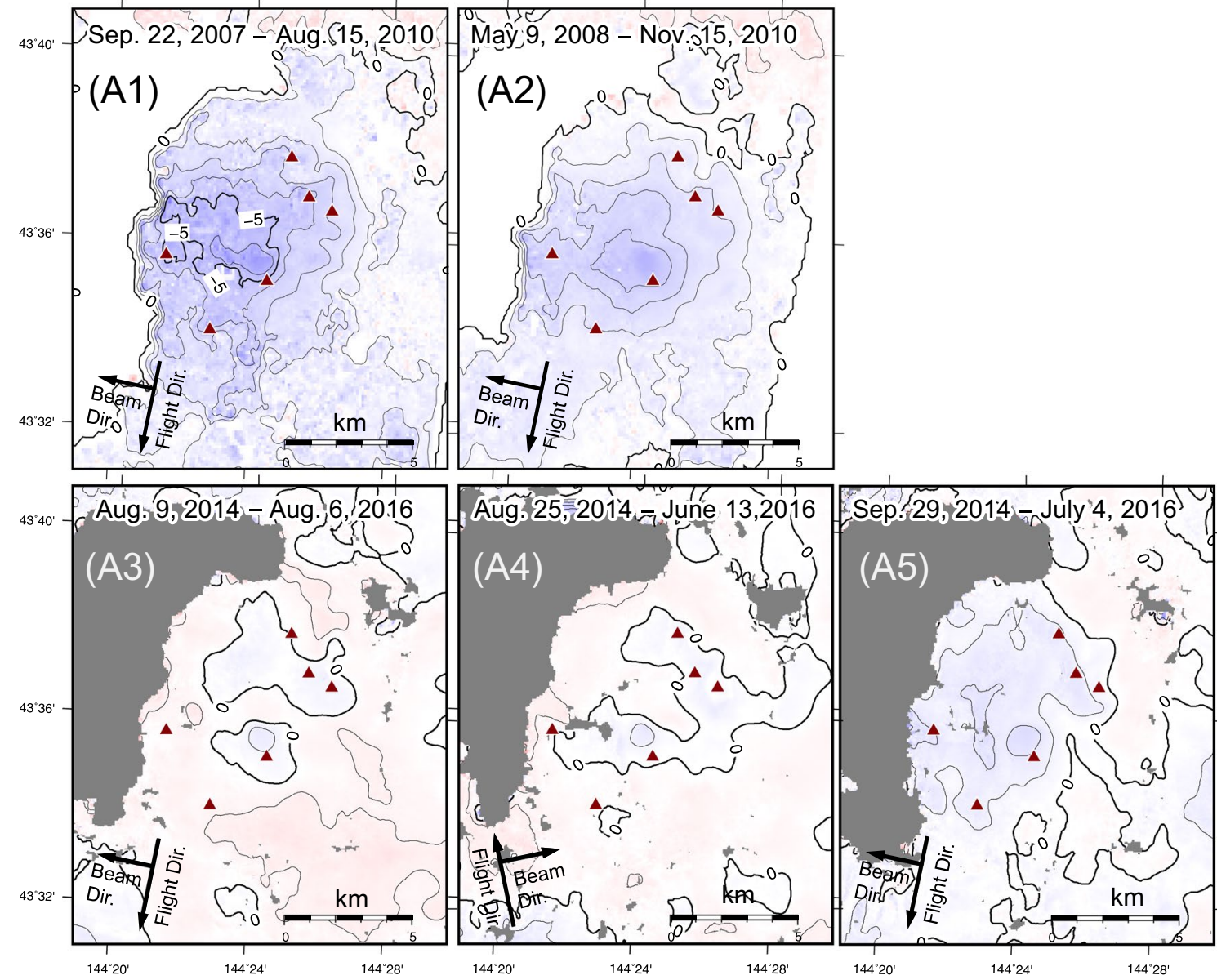

Fig. 5 Unwrapped SAR interferograms of ALOS and ALOS-2 used in this study. Each number indicates the InSAR pair in Table 1. Red triangles indicate major lava domes belonging to the Atosanupuri volcanic complex. Contour interval is $1 \mathrm{~cm}$. The target area is shown in Fig. 1

the corrected maximum displacement for each interferogram is shown in Table 1 . The effects of the small-scale deformations are small, and the changes in the maximum displacement are $<1 \mathrm{~cm}$ (Table 1 , except for a noisy InSAR pair 3). Based on these corrected values, the temporal evolution of the maximum vertical displacement in each interferogram near the center of the deformation field (assuming the horizontal component of displacement was suitably small near the center) is shown in Fig. 9. Figure 9 shows changes in the three periods of (1) JERS-1 (1993-1998), (2) ALOS (2007-2010), and (3)
ALOS-2 (2014-). As the SAR data of the three satellites have different specifications, only the relative variations within each period are available; therefore, a continuous total displacement cannot be determined. Interestingly, in period (2), that is, 10 years later than (1), subsidence subsequent to (1) was also found. Unfortunately, the interferograms of each of the three satellites were not directly comparable; however, the rate of subsidence in (2) was likely larger than the extension of the natural subsidence process (e.g., exponential decay) following period (1). Furthermore, although the subsequent period (3) was 


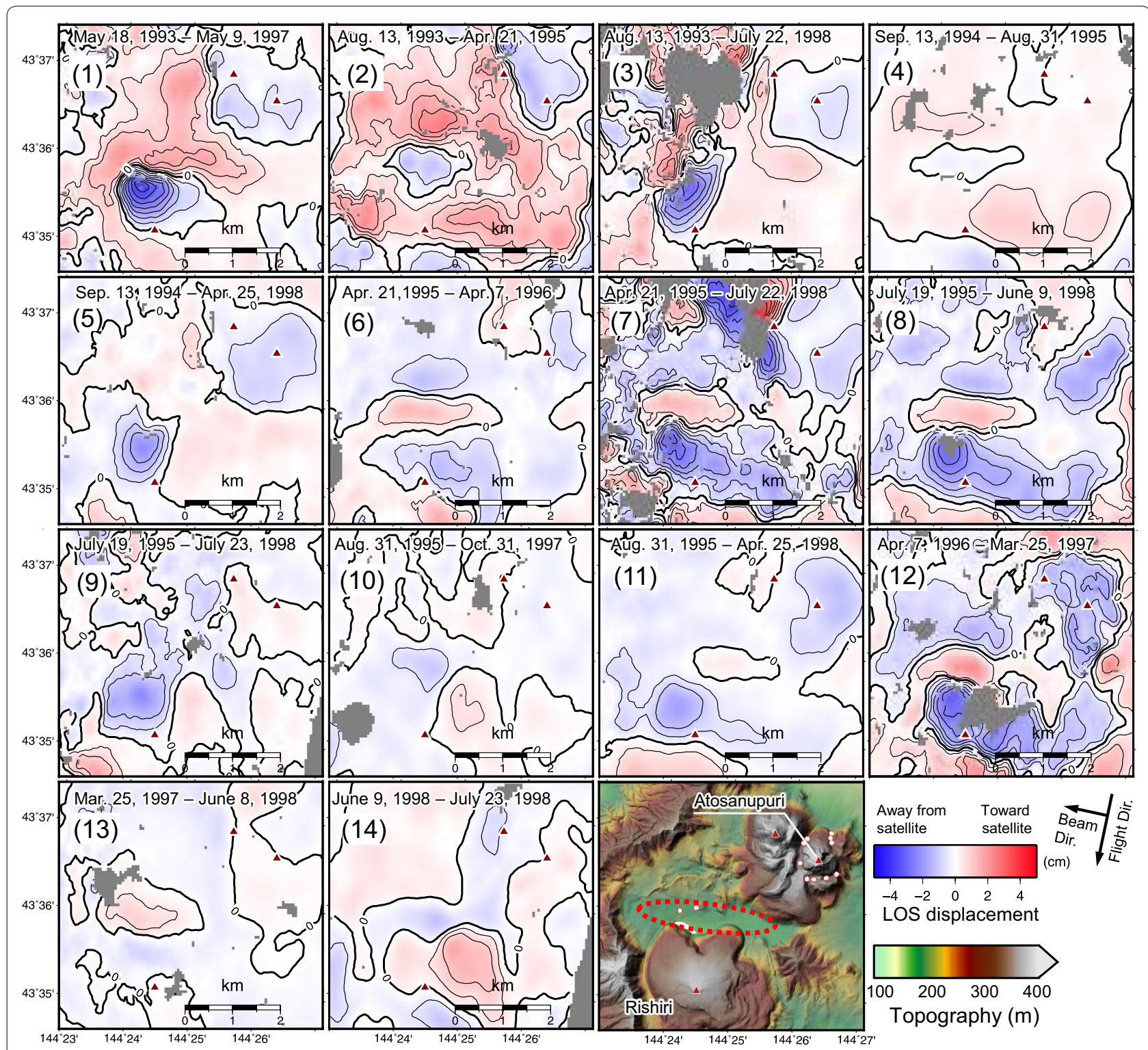

Fig. 6 High-pass-filtered (7-km cutoff) close-up view of unwrapped interferograms around the center of the deformation dome. Each number indicates the InSAR pair in Table 1. Red triangles indicate major lava domes belonging to the Atosanupuri volcanic complex. Contour interval is $0.5 \mathrm{~cm}$. Lower right: Topography of the Atosanupuri volcanic complex. Red dotted lines show the area of a small valley (or basin) between lava domes in the topography. Small white circles show fumaroles. The target area is shown in Fig. 1

short, significant subsidence was not found. From these facts, it is unlikely that the subsidence process relaxed naturally with a certain time constant after (1). There is a possibility that a process of uplift occurred again within this period or that the rate of subsidence fluctuated with time. Indeed, a small uplift related to a slight increase in the number of earthquakes (swarm) was found in 1998 (Fig. 3), suggesting there was more than one uplift-subsidence process. The two earthquake swarms recorded in the Kussharo caldera in 1994 and 1998 both accompanied or slightly preceded uplift. This type of relationship between deformation and earthquake swarm within a volcanic area has been found in both Yellowstone (Wicks et al. 2006) and Hawaii of the USA (Wolfe et al. 2004). As subsidence had ceased by 2014, the time constant of the subsidence is most probably $<20$ years.

We also recalculated the volcanic source parameters shown in Table 2 using the corrected interferograms. In the calculation of the corrected interferograms, the available data area was reduced because of the averaging of 


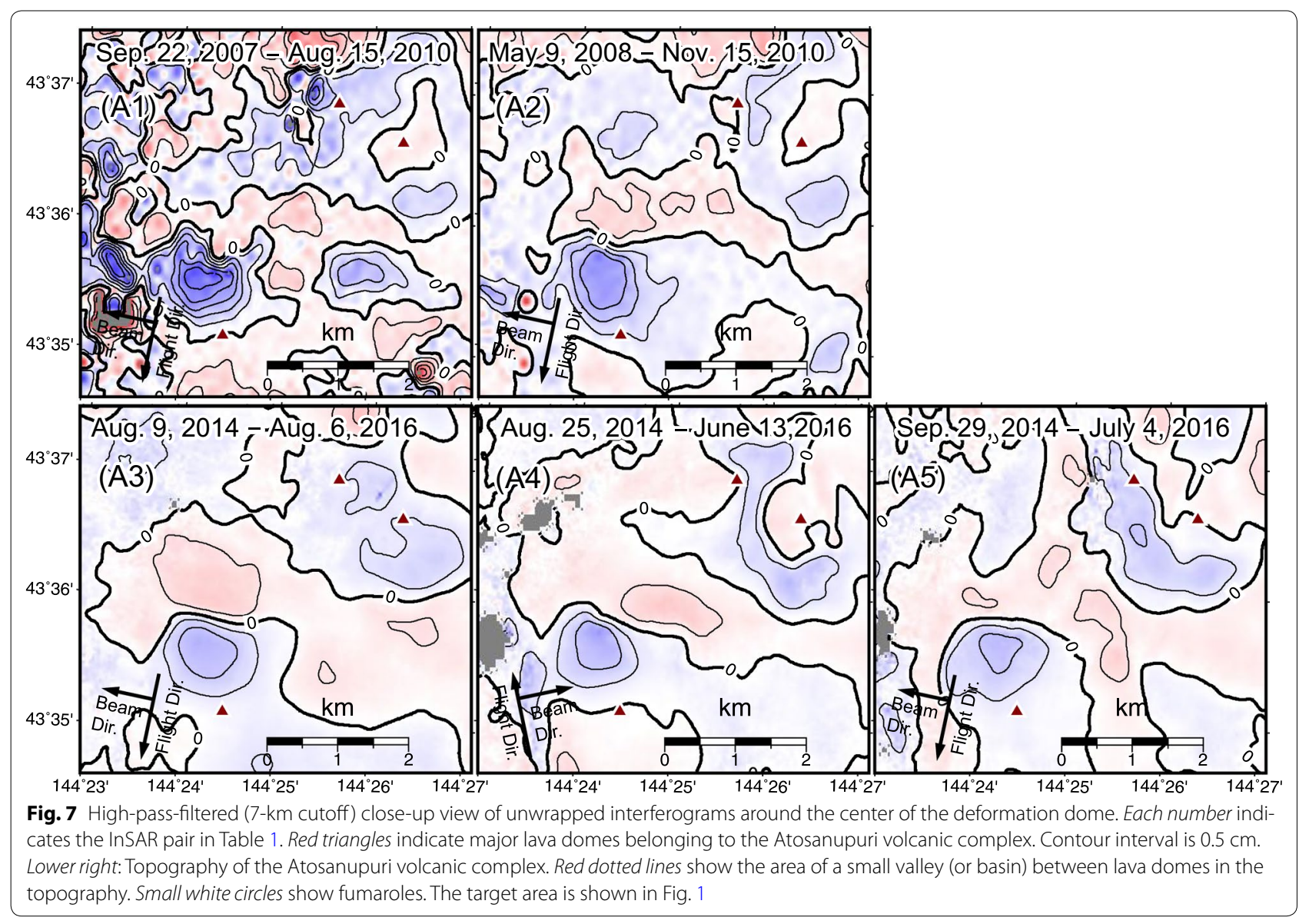

several decorrelated interferograms. Then, we inverted the deformations to estimate the open parameter of the sill. After the correction of the small-scale deformations, the open parameter in Table 2 changed by $+0.05 \mathrm{~m}$ for the uplift interferogram and by $-0.01 \mathrm{~m}$ for the subsidence interferogram, and we confirm these values are within the error level. The modeled depth of the source and the increase in volume were similar to those of the Three Sisters volcanic center in the USA. (Wicks et al. 2002).

There are two possible mechanisms for the uplift: (1) migration of magmatic fluids from deeper to shallower parts (Chang et al. 2010; Wicks et al. 2006) and (2) hydrothermal fluid (water and gases) activity (WilliamsJones et al. 2003). However, hydrothermal fluid activities are often found at depths $<5 \mathrm{~km}$ in other volcanoes such as the Campi Flegrei caldera in Italy (Battaglia et al. 2006) and by numerical simulations (Hutnak et al. 2009). Honda et al. (2011) reported that a low-resistivity ( 10 $\Omega \mathrm{m})$ structure exists just under the Atosanupuri lava dome and that melts with very low resistivity $(\sim 1 \Omega \mathrm{m})$ probably exist at or deeper than $14 \mathrm{~km}$. As the upper depth of the low-resistivity structure is approximately
$6 \mathrm{~km}$, the magma probably climbed to the depth of the sill and then migrated laterally, forming a new sill or opening a pre-existing sill. The increase in seismicity can also be explained by changes in the stresses induced by inflation of the sill. We infer that in late 1993 or early 1994, the magma that likely gained buoyancy by some mechanism, presumably via vesiculation, began to ascend from deep below the surface. The total magma volume that contributed to the inflation of the sill was more than $2 \times 10^{7} \mathrm{~m}^{3}$ by the middle of 1995 (Table 2). Although the interferograms do not show deformation of the deflating magma reservoir, they do show there was no lateral transport of mass. In the case of a propagating dyke coupled to a magma chamber, Irwan et al. (2006), Rivalta (2010), and Segall et al. (2001) showed that the volume of an inflating dyke is more than three times that of a deflating spherical magma chamber; therefore, the magma probably came from just under the sill and the deformation of the deflating magma reservoir was hidden or overlapping within the deformation field of the inflating sill.

The subsidence began around the summer of 1995. By the summer of 1998, the net volume of the sill during the 


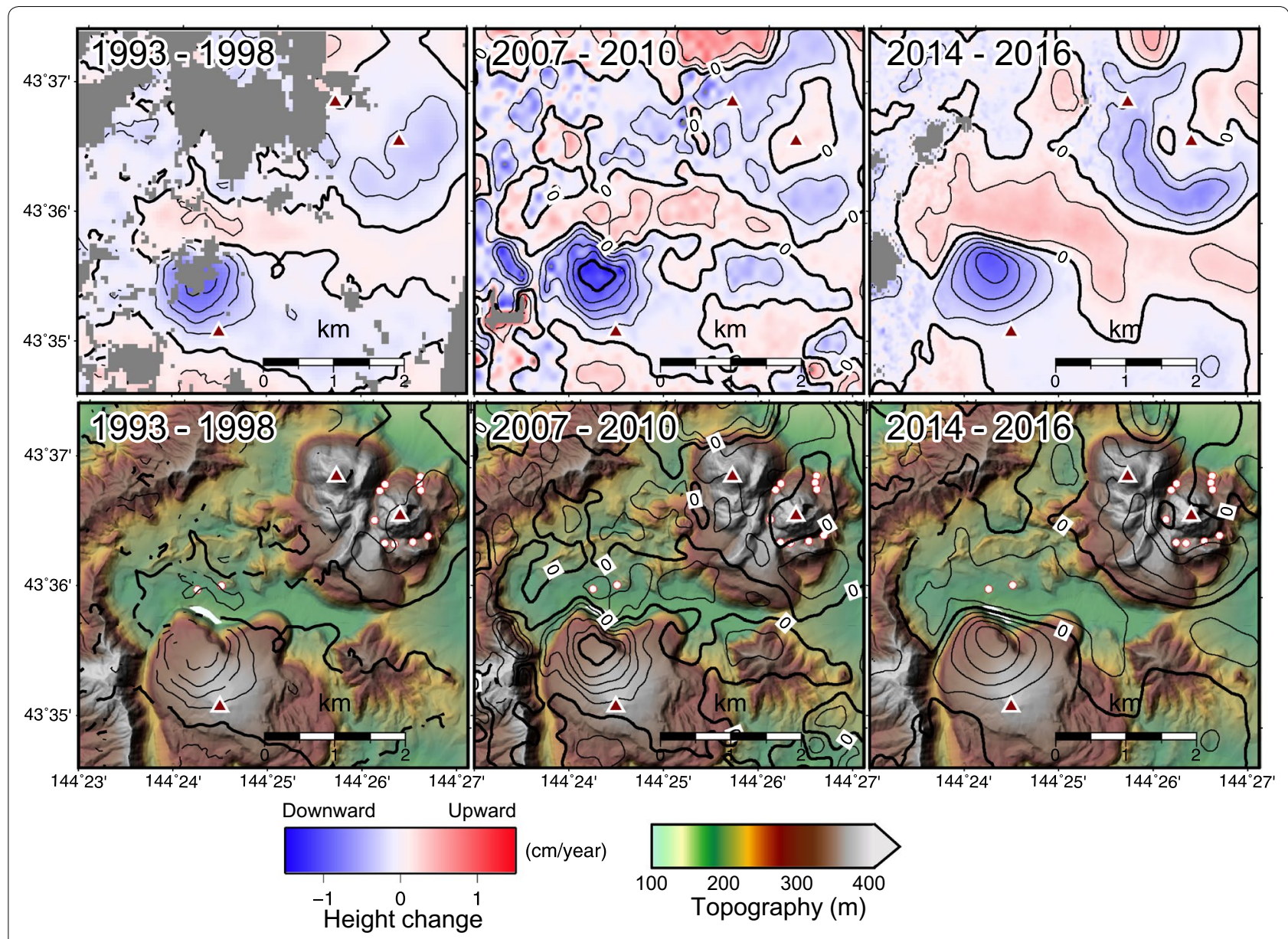

Fig. 8 Average yearly rate of height change. Contour interval is $0.2 \mathrm{~cm}$. Left figures are calculated from InSAR pairs 1, 3, 5, 7, 8, 9, and 11, center figures from A1 and A2, and right figures from A3, A4, and A5. In the lower figures, the same contours are drawn on the topography as in the upper figures. The target area is shown inFig. 1

entire process decreased to about $1 \times 10^{7} \mathrm{~m}^{3}$ (Table 2), which is approximately half the volume of the inflation that occurred during 1993-1995. The model simulation (Table 2) suggests that uplift and subsidence have the same source; therefore, there are several possible mechanisms for the subsidence: (1) drainback of the magma; (2) contraction of hot crystalline rock during cooling; and (3) densification of a cooling magma body during crystallization (Dzurisin et al. 2002). The contraction of rock during cooling cannot account fully for the deformation. The coefficients of the thermal expansion for gabbro and granite under standard conditions are $1.6 \times 10^{-5} /{ }^{\circ} \mathrm{C}$ and $2.4 \times 10^{-5} /{ }^{\circ} \mathrm{C}$ (Turcotte and Schubert 1982). If the temperature decreased by $1000{ }^{\circ} \mathrm{C}$, a volume change of only several percent would occur. The third mechanism, crystallization, explains $20 \%$ of the volume change at most (Caricchi et al. 2014). Viscoelasticity might explain that the deformation shown in Fig. 9 relaxed exponentially with time (Yokoyama 2013) and that the viscoelasticity affected both the uplift and the subsidence. Dragoni and Magnanensi (1989) highlighted that seismic activity began after the onset of ground uplift in the Campi Flegrei caldera because of viscoelasticity; however, the two earthquake swarms in the Kussharo caldera each accompanied or slightly preceded the uplifts. Although the combination of cooling, crystallization of the magma, and viscoelasticity might have contributed to part of the subsidence, a downward drainback of magma remains the most probable mechanism for the subsidence.

As the horizontal distribution of the lava domes of the Atosanupuri volcanic complex and the top of the lowresistivity structure almost match the dimensions of the sill, we speculate the sill likely persists there and that it has been operating as a secondary magma reservoir of the volcanic complex from the past. Similar changes from uplift to subsidence have been observed in the Yellowstone caldera, and Wicks et al. (2006) inferred continuous 


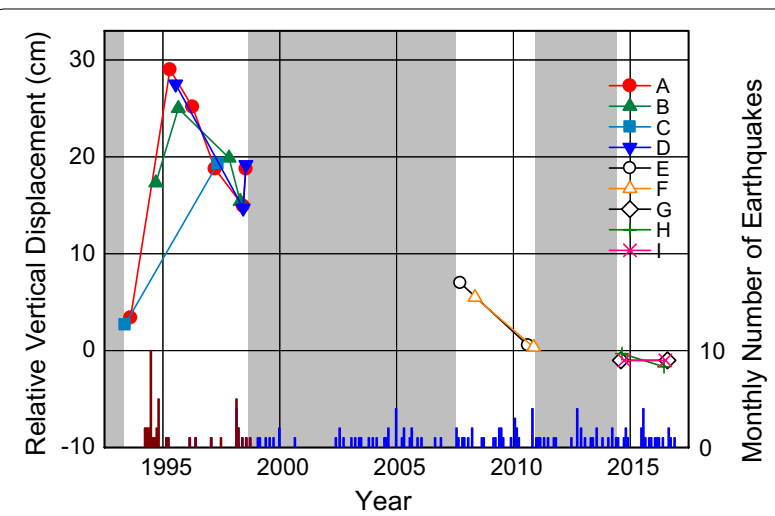

Fig. 9 Temporal evolution of the maximum vertical displacement in each interferogram near the center of the deformation field. Each time series A-I shows independent time change defined in Table 1. In this figure, each time series is shifted vertically to show the smallest variation between the time series. Gray areas show no periods with InSAR data, and the vertical displacement time series do not have the same relationship with each other before and after the gray areas. Monthly number of earthquakes within the region (Fig. 2) is also plotted: Brown bars show those from 1993 to 1998 after Earthquake Research Institute (2002), and blue bars show those from 1999 to 2016 processed by the Japan Meteorological Agency (JMA). Earthquakes include those with magnitudes of more than 0.3 and depths shallower than $20 \mathrm{~km}$. Given the revisions of observation points (etc.), the quality of seismic data is not uniform over time

movement of molten basalt into and out of the Yellowstone volcanic system. As our study lacks concrete evidence supporting the assertion of magma withdrawal as the cause of subsidence, measurements of microgravity change (de Zeeuw-van et al. 2005; Williams-Jones et al. 2003) would support such an analysis in future monitoring of the volcano.

The above scenario raises two questions. (1) Why was the ascent of magma blocked at the depth of $6 \mathrm{~km}$, forcing the magma to migrate laterally? (2) Why did subsidence of the volcano follow the uplift? One possible answer to the first question is that there might be a vertical density gap at the depth of $6 \mathrm{~km}$ and that the buoyancy of the magma (Taisne et al. 2011; Wicks et al. 2006) might have been sufficient to rise through the lower and denser mother rock, but not to ascend through the lighter upper layer. On the other hand, a change in fracture orientation and/or stress conditions might have allowed lateral intrusion of the sill instead of vertical migration (Taisne et al. 2011). Thus, as the supply of new magma from deep below the surface continued, there was no other route for the stagnant magma, which was blocked from rising further, other than to migrate laterally. The answer to the second question might be that the initial rate of magma supply from depth decreased and that gradual degassing from the magma remaining in the sill after the ascent reduced its buoyancy, which resulted in the descent or drainback of magma to depths further below the surface (Moran et al. 2011).

\section{Concluding remarks}

The InSAR observations revealed that two types of deformation occurred silently under the Atosanupuri volcanic complex. One type comprised the deformation sequence from uplift to subsidence during 1993-2016. As the deformation had a similar shape throughout the sequence, the deformation could be attributed to a common source. The second type was the small constant subsidence of some lava domes with small-scale patterns throughout the three periods 1993-1998, 2007-2010, and 2014-2016. At the time of deformation, the volcano was not under observation by either the GNSS or any other continuous crustal deformation monitoring system (e.g., tiltmeters or extensometers); therefore, this volcanic event remained unrecognized until the retrospective satellite analysis presented in this study revealed the associated deformation. As this deformation occurred in a volcanic dome that does not show remarkable active volcanic phenomena, continuous monitoring of the Atosanupuri volcanic complex is essential for assessing the potential for future eruptions.

The use of three different SAR satellites meant it was possible to detect the long-lasting crustal deformation sequence. However, the absolute changes in the long-term deformation process could not be established because the interferograms of each of the three satellites were not directly comparable. We hope that future SAR satellites will have capabilities that allow the construction of interferograms comparable with past satellites, and that they will help uncover volcanic activities from the past to the future.

\section{Additional file}

Additional file 1. Fig. S1 Daily vertical displacement observed at GNSS stations around the Kussharo caldera. Fig. S2 Unwrapped SAR interferograms after the small-scale constant deformation correction.

\section{Authors' contributions}

SF analyzed the interferograms and drafted the manuscript. MM and TN constructed the synthetic models, and MT, HY, and TK supported in the construction of the interferograms. All authors read and approved the final manuscript.

\section{Author details}

${ }^{1}$ Geospatial Information Authority of Japan, 1 Kitasato, Tsukuba, Ibaraki 305-0811, Japan. ${ }^{2}$ Hokkaido University, Kita 10 Nishi 8, Kita-ku, Sapporo, Hokkaido 060-0810, Japan. ${ }^{3}$ Kyoto University, Gokasho, Uji, Kyoto 611-0011, Japan.

\section{Acknowledgements}

The JERS-1 SAR data used in this study were provided by JAXA. Ministry of Economy, Trade and Industry of Japan (METI) and JAXA retain the ownership of the original data. The Geospatial Information Authority of Japan (GSI) 
obtained ALOS/PALSAR data through the "Joint Cooperative Agreement between GSI and JAXA for observation of geographic information using ALOS data." Ownership of the ALOS/PALSAR data is retained by JAXA and METI. ALOS-2 data were provided under a cooperative research contract with JAXA. Ownership of ALOS-2 data is retained by JAXA. We used the earthquake data file "Japan University Network Earthquake Catalog Hypocenters File." Hypocenter data processed by the Japan Meteorological Agency (JMA) were used.

\section{Competing interests}

The authors declare that they have no competing interests.

\section{Publisher's Note}

Springer Nature remains neutral with regard to jurisdictional claims in publishedmaps and institutional affiliations.

Received: 7 March 2017 Accepted: 29 May 2017

Published online: 08 June 2017

\section{References}

Battaglia M, Troise C, Obrizzo F, Pingue F, de Natale G (2006) Evidence for fluid migration as the source of deformation at Campi Flegrei caldera (Italy). Geophys Res Lett 33:L01307. doi:10.1029/2005GL024904

Berardino P, Fornaro G, Lanari R, Sansosti E (2002) A new algorithm for surface deformation monitoring based on small baseline differential SAR interferograms. IEEE Trans Geosci Remote Sens 40:2375-2383. doi:10.1109/ TGRS.2002.803792

Caricchi L, Biggs J, Annen C, Ebmeieret S (2014) The influence of cooling, crystallisation and re-melting on the interpretation of geodetic signals in volcanic systems. Earth Planet Sci Lett 388:166-174. doi:10.1016/j. epsl.2013.12.002

Chang W-L, Smith RB, Farrell J, Puskas CM (2010) An extraordinary episode of Yellowstone caldera uplift, 2004-2010, from GPS and InSAR observations. Geophys Res Lett 37:L23302. doi:10.1029/2010GL045451

Chaussard E, Amelung F, Aoki Y (2013) Characterization of open and closed volcanic systems in Indonesia and Mexico using InSAR time series. J Geophys Res Solid Earth 118:3957-3969. doi:10.1002/jgrb.50288

de Zeeuw-van Dalfsen E, Rymer H, Sigmundsson F, Sturkell E (2005) Net gravity decrease at Askja volcano, Iceland: constraints on processes responsible for continuous caldera deflation, 1988-2003. J Volcanol Geotherm Res 139:227-239

Dragoni M, Magnanensi C (1989) Displacement and stress produced by a pressurized, spherical magma chamber, surrounded by a viscoelastic shell: Phys Earth Planet Inter 56:316-328. doi:10.1016/0031-9201(89)90166-0

Dzurisin D, Poland MP, Burgmann R (2002) Steady subsidence of Medicine Lake volcano, northern California, revealed by repeated leveling surveys. J Geophys Res 107:2372. doi:10.1029/2001 JB000893

Earthquake Research Institute (2002) Japan University Network Earthquake Catalog. http://wwweic.eri.u-tokyo.ac.jp/CATALOG/junec/. Accessed 8 Dec 2016

Fialko Y, Simons M (2001) Evidence for on-going inflation of the Socorro Magma Body, New Mexico, from interferometric synthetic aperture radar imaging. Geophys Res Lett 28:3549-3552. doi:10.1029/2001GL013318

Fournier TJ, Pritchard ME, Riddick SN (2010) Duration, magnitude, and frequency of subaerial volcano deformation events: new results from Latin America using InSAR and a global synthesis. Geochem Geophys Geosyst 11:Q01003. doi:10.1029/2009GC002558

Fujiwara S, Tobita M (1999) SAR interferometry techniques for precise surface change detection. J Geod Soc Jpn 45:283-295 (in Japanese with English abstract)

Fujiwara S, Rosen PA, Tobita M, Murakami M (1998) Crustal deformation measurements using repeat-pass JERS 1 synthetic aperture radar interferometry near the Izu Peninsula, Japan. J Geophys Res 103:2411-2426. doi:10.1029/97JB02382

Fujiwara S, Tobita M, Murakami M, Nakagawa H, Rosen PA (1999) Baseline determination and correction of atmospheric delay induced by topography of SAR interferometry for precise surface change detection. J Geod Soc Jpn 45:315-325 (in Japanese with English abstract)
Geospatial Information Authority of Japan (2016) Digital elevation model of fundamental geospatial data. https://fgd.gsi.go.jp/download/ref_dem. html. Accessed 16 April 2017 (in Japanese)

Goldstein R, Werner C (1998) Radar interferogram filtering for geophysical application. Geophys Res Lett 25:4035-4038

Goldstein R, Zebker H, Werner C (1998) Satellite radar interferometry: twodimensional phase unwrapping. Radio Sci 23:713-720

Hanssen R (2001) Radar Interferometry: data interpretation and error analysis. Kluwer, Dordrecht

Hasegawa T, Kishimoto H, Nakagawa M, Itoh J, Yamamoto T (2009) Eruptive history of post-caldera volcanoes of Kutcharo caldera, eastern Hokkaido, Japan, as inferred from tephrostratigraphy in the Konsen and Shari areas for the period 35-12 ka. J Geol Soc J.jn 115:369-390 (in Japanese with English abstract)

Hasegawa T, Nakagawa M, Kishimoto H (2013) The eruption history and silicic magma system of caldera forming eruptions in eastern Hokkaido, Japan. J Mineral Petrol Sci 107:39-43

Honda R, Yamaya Y, Ichihara H, Hase H, Mogi T, Yamashita H, Ohyama T, Uyeshima M, Nakagawa M (2011) Magnetotelluric investigation around the Kutcharo caldera region. Geophys Bull Hokkaido Univ 74:45-55. doi:10.14943/gbhu.74.45 (in Japanese with English abstract)

Hooper A, Zebker H, Segall P, Kampes B (2004) A new method for measuring deformation on volcanoes and other natural terrains using InSAR persistent scatterers. Geophys Res Lett 31:L23611. doi:10.1029/2004GL021737

Hutnak M, Hurwitz S, Ingebritsen SE, Hsieh PA (2009) Numerical models of caldera deformation: effects of multiphase and multicomponent hydrothermal fluid flow. J Geophys Res 114:B04411. doi:10.1029/2008JB006151

Irwan M, Kimata F, Fujii N (2006) Time dependent modeling of magma intrusion during the early stage of the 2000 Miyakejima activity. J Volcanol Geotherm Res 150:202-212

Japan Meteorological Agency (2013) National catalogue of the active volcanoes in Japan (Fourth Edition), 5. Atosanupuri. http://www.data.jma. go.jp/svd/vois/data/tokyo/STOCK/souran_eng/volcanoes/005_atosanupuri.pdf. Accessed 23 Nov 2016

Katsui Y (1962) Geological map of Japan, "Kutcharo-ko" with explanatory text. 1-42. Geological Survey Jpn, Tsukuba (in Japanese with English abstract)

Katsui Y, Yokoyama I, Okada H, Nishida Y, Matsumoto T, Kawakami N (1986) Atosanupuri Mashu (Kamuinupuri), its volcanic geology, history of eruption, present state of activity and prevention of disasters. Committee Prevention Disasters Hokkaido, Sapporo (in Japanese)

Matsu'ura M, Hasegawa Y (1987) A maximum likelihood approach to nonlinear inversion under constraints. Phys Earth Planet Inter 47:179-187

Mogi K (1958) Relations between the eruptions of various volcanoes and the deformations of the ground surfaces around them. Bull Earthq Res Inst 36:99-134

Moran SC, Newhall C, Roman DC (2011) Failed magmatic eruptions: latestage cessation of magma ascent. Bull Volcanol 73:115. doi:10.1007/ s00445-010-0444-x

Motoya Y, Ichiyanagi M (1996) Seismic activity near Atosanupuri in Teshikaga region eastern part of Hokkaido, Japan (1925-1995). Geophys Bull Hokkaido Univ 59:211-220. doi:10.14943/gbhu.59.211 (in Japanese with English abstract)

Murakami H (1995) Accuracy estimation of digital map series data sets published by the geographical survey institute. Geoinfomatics 6:59-64 (in Japanese with English abstract)

Okada Y (1985) Surface deformation due to shear and tensile faults in a halfspace. Bull Seismol Soc Am 75:1135-1154

Rivalta E (2010) Evidence that coupling to magma chambers controls the volume history and velocity of laterally propagating intrusions. J Geophys Res 115:B07203. doi:10.1029/2009JB006922

Rosen PA, Hensley S, Zebker HA, Webb FH, Fielding EJ (1996) Surface deformation and coherence measurements of Kilauea Volcano, Hawaii, from SIR-C radar interferometry. J Geophys Res 101:23109-23125

Segall P (2010) Earthquake and volcano deformation. Princeton University Press, Princeton

Segall P, Cervelli P, Owen S, Lisowski M, Miklius A (2001) Constraints on dike propagation from continuous GPS measurements. J Geophys Res Solid Earth 106:19301-19317

Taisne B, Tait S, Jaupart C (2011) Conditions for the arrest of a vertical propagating dyke. Bull Volcanol 73:191. doi:10.1007/s00445-010-0440-1 
Tobita M (2003) Development of SAR interferometry analysis and its application to crustal deformation study. J Geod Soc Jpn 49:1-23 (in Japanese with English abstract)

Tobita M, Fujiwara S, Ozawa S, Rosen PA, Fielding EJ, Werner CL, Murakami M, Nakagawa H, Nitta K, Murakami M (1998) Deformation of the 1995 North Sakhalin earthquake detected by JERS-1/SAR interferometry. Earth Planets Space 50:313-325. doi:10.1186/BF03352118

Tobita M, Fujiwara S, Murakami M, Nakagawa H, Rosen PA (1999) Accurate offset estimation between two SLC images for SAR interferometry. J Geod Soc Jpn 45:297-314 (in Japanese with English abstract)

Turcotte DL, Schubert G (1982) Geodynamics: applications of continuum physics to geological problems. Wiley, New York

Wicks CW Jr, Dzurisin D, Ingebritsen S, Thatcher W, Lu Z, Iverson J (2002) Magmatic activity beneath the quiescent Three Sisters volcanic center, central Oregon Cascade Range, USA. Geophys Res Lett 29:1122. doi:10.10 29/2001GL014205
Wicks C, Thatcher W, Dzurisin D, Svarc J (2006) Uplift, thermal unrest, and magma intrusion at Yellowstone caldera, observed with InSAR. Nature 440:72-75. doi:10.1038/nature04507

Williams-Jones G, Rymer H, Rothery DA (2003) Gravity changes and passive $\mathrm{SO}_{2}$ degassing at the Masaya caldera complex, Nicaragua. J Volcanol Geotherm Res 123:137-160

Wolfe CJ, Okubo PG, Ekström G, Nettles M, Shearer PM (2004) Characteristics of deep ( $\geq 13 \mathrm{~km}$ ) Hawaiian earthquakes and Hawaiian earthquakes west of 155.55W. Geochem Geophys Geosyst 5:6. doi:10.1029/2003GC000618

Yokoyama I (2013) An interpretation on secular changes in deformation caused by the 1914 Eruption of Sakurajima Volcano. Bull Volcanol Soc Jpn 58:77-90

\section{Submit your manuscript to a SpringerOpen ${ }^{\circ}$ journal and benefit from:}

- Convenient online submission

- Rigorous peer review

- Immediate publication on acceptance

- Open access: articles freely available online

- High visibility within the field

- Retaining the copyright to your article 